\title{
Tribological properties of the directionally oriented warp knit GFRP composites
}

\author{
M.T. Mathew ${ }^{\text {a }}$, Naveen V. Padaki ${ }^{b}$, L.A. Rocha ${ }^{\text {a,c }}$, J.R. Gomes ${ }^{\text {a,c, }}$, \\ R. Alagirusamy ${ }^{\text {, }}$, B.L. Deopura ${ }^{\text {b }}$, R. Fangueiro ${ }^{d}$ \\ ${ }^{a}$ Research Centre on Interfaces and Surfaces Performance (CIICS), Azurém, Guimarães 4800-058, Portugal \\ ${ }^{\mathrm{b}}$ Department of Textile Technology, Indian Institute of Technology-Delhi, Hauz Khas, New Delhi 110 016, India \\ ${ }^{\mathrm{c}}$ Department of Mechanical Engineering, University of Minho, Campus de Azurém, Guimarães 4800-058, Portugal \\ ${ }^{\mathrm{d}}$ Department of Textile Engineering, University of Minho, Campus de Azurem, Guimarães 4800-058, Portugal \\ Received 11 September 2006; received in revised form 14 December 2006; accepted 18 December 2006
}

\begin{abstract}
Recently, directionally oriented warp knit structures have gained prominence as reinforcements in composite materials due to their superior isotropic behaviour compared to other types of textile reinforcements. In the present study, composites prepared from four types of directionally oriented warp knit glass preforms with three different thermoset resins have been considered for the tribological characterisation. The tribological tests have been conducted on a reciprocating sliding test rig with ball-on-plate configuration. The tests were conducted in dry (unlubricated) and wet (aqueous) conditions at a fixed applied load $(100 \mathrm{~N})$ by varying the sliding distance. E-glass warp knitted preforms were used for the study including biaxial, biaxial non-woven, triaxial and quadraxial fabrics. The matrices were three different thermoset resins namely polyester, vinyl ester and epoxy resin.
\end{abstract}

The main aim of the study was to identify a composite having the best tribological performance, with regard to types of preform and matrix resin. Moreover, the results obtained from the tests have been used to develop a wastage map for these composites, as a function of sliding distance and type of preform in order to have a clear understanding of the tribological process.

(C) 2007 Published by Elsevier B.V.

Keywords: Textile preforms; Directionally oriented structures; Resins; Sliding distance; Wear mechanisms; Wastage map

\section{Introduction}

Fibre reinforced composites have been used successfully for many decades as engineering materials; they have been designed and manufactured for various applications such as maritime craft, aircraft, automobiles, civil and many structural end uses [1]. Textile preforms have major advantages such as ease of handling, net-shapability and high versatile design potential due to the structural complexity [2]. Hence they have been a prime reinforcement for the composite applications [3].

In tribological applications, these composites are subjected to conditions such as rubbing, sliding, rolling against themselves or against other materials. In multifaceted situations, there may be liquid or other foreign bodies present at the contact zone

\footnotetext{
* Corresponding author.

E-mail address: jgomes@dem.uminho.pt (J.R. Gomes).
}

or interfaces of the contacting bodies. For the effective use of such composite materials, they should exhibit good tribological properties. Some of the practical examples for the use of the fibre reinforced composites are vehicle brake-shoe and ice-skating board applications in which they have to function with rubbing on the surfaces of other materials and also abrasive particles which may be entrapped between the interfaces of the materials.

Over the last three decades, the investigation on wear and friction characteristics of many polymer composites were reported, such as carbon fibre reinforced polymer composites [4], mica-filled fibre-reinforced epoxy resin composites [5] and unidirectional graphite-epoxy and carbon-PEEK composites [6]. The tribological parameters, such as load, sliding distance or duration, sliding speed, sliding conditions etc. were considered for evaluating the effect on tribological performance of such composites [7-12]. The tribological properties were found to depend on the type of resin, size, shape and orientation of the fibres used for the reinforcements. One of the preliminary 

Nomenclature
BANW biaxial non-woven structure
BAWK biaxial warp knit structure
DOS directionally oriented warp knit structures
ER epoxy resin
MAWK multi-axial warp knits (same as DOS)
PE polyester resin (unsaturated)
QAWK quadraxial warp knit structure
TAWK triaxial warp knit structure
VE vinyl-ester resin

investigations on the effect of fibre orientation on tribological characterisation of fibre reinforced composites was reported by Sung et al. [7]. However, many of the studies considered unidirectional fibre orientations or short fibre-reinforced polymer composites [8,9]. Directionally oriented warp knits are the new textile preforms in which the fibres are oriented in desired directions in different planes to get preferred preform properties in various directions. Hence, such advancements in preform engineering call for evaluation of the tribological properties of a new class of polymer composites in order to understand and improve their usability and durability.

Consequently, in this study, tribological tests are conducted on vinyl-ester resin composites reinforced with four different directionally oriented warp knit preforms, namely; biaxial (BAWK), biaxial non-woven (BANW), Triaxial (TAWK) and Quadraxial (QAWK) preforms. The study was also extended to the QAWK reinforced composites with three different thermoset resin matrices i.e., vinyl-ester, epoxy and polyesters. The primary objective of the study was to identify the best composite composition amongst the preforms and resins with respect to tribological properties.

\section{Experimental details}

\subsection{Material}

(a) Textile preforms

Amongst the textile preforms, directionally oriented warp knit structures (DOS) or multi-axial warp knits (MAWK) have evolved through structural modifications of warp knitted fabrics with inlay yarns in horizontal $\left(\right.$ weft- $90^{\circ}$ ), vertical (wale- $0^{\circ}$ ) and diagonal $\left( \pm 45^{\circ}\right)$ directions. They are also termed as the non-crimp structures since the presence of knitted loops is assisting to hold layers of uncrimped inlay yarns. The amount of fibre and orientation in controlled directions are certainly an advantage for the preform engineering. Moreover, the mechanical properties of textile composites are mainly designed based on the fibre properties. Liba and Malimo systems along with such inlay knit layers can as well incorporate fibre / non-woven fleece between the layers to produce multi-axial multi-layer structures [13] most of these DOS are predominantly applied for composite reinforcements. Four types of multi-axial warp knit preforms, i.e., biaxial (BAWK), biaxial non-woven (BANW), Triaxial (TAWK) and Quadraxial (QAWK) oriented warp knit as shown in the Fig. 1, were used for the present studies. The E glass fibres were used for the fabric and the knitting yarn (bind yarn) used was Polyester (50 Denier). The fabric characteristics and construction details are presented in Table 1. The inlay E glass roving in different directions of the MAWK structure are mentioned as $0^{\circ}$ along wale, $90^{\circ}$ along course and $\pm 45^{\circ}$ along bias directions.

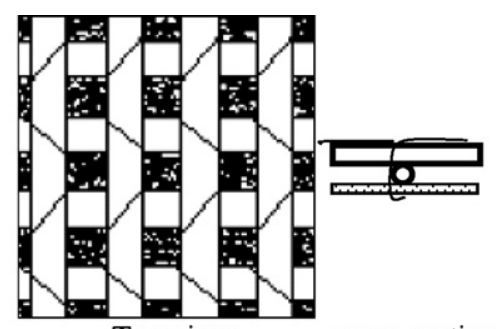

Top view cross section Biaxial non-woven (0/90/non-woven) - BANW

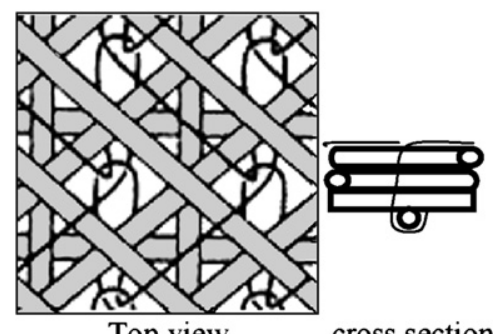

Top view cross section Quadraxial (+45/-45/0/90) - QAWK

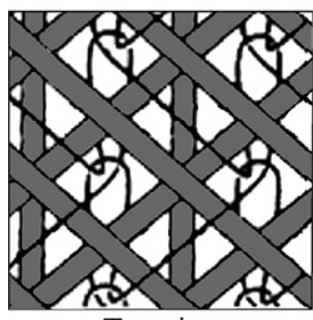

Top view Triaxial $(+45 /-45 / 90)$ - TAWK cross section

Multiaxial Warp Knit Structures

Fig. 1. Schematic diagram of multi-axial warp knit structures or preforms (BANW, BAWK, TAWK, QAWK). 
Table 1

Multi-axial warp knit fabric specifications

\begin{tabular}{|c|c|c|c|}
\hline Preforms & Glass inlay yarn (Tex) & Preform thickness (mm) & Weight $\left(\mathrm{g} / \mathrm{m}^{2}\right)$ \\
\hline Biaxial DOS (BAWK) & $200(+45 /-45)$ & 0.81 & 406 \\
\hline Biaxial non-woven DOS (BANW) & $1200(0) 400(90)$ & 1.22 & 786 \\
\hline Triaxial DOS (TAWK) & $900(0) 300(+45 /-45)$ & 1.12 & 787 \\
\hline Quadraxial DOS (QAWK) & $600(0) 300(+45 /-45 / 90)$ & 1.62 & 802 \\
\hline
\end{tabular}

(b) Resins

Three different thermoset resins, i.e., vinyl-ester, epoxy and polyester, have been used for the present study. Among these thermoset resins, epoxy has certain advantages over polyester and vinyl ester resins with better fatigue life, impact resistance, corrosion resistance and also higher glass transition temperature [14].

(c) Composites

The composite laminates from these preforms were prepared by hand lay-up technique. All the three resins used in the current study, were curable at ambient temperature. Hence, the impregnated performs were cured for $24 \mathrm{~h}$ at room temperature between two parallel plates loaded with $5 \mathrm{~kg}$ dead weight, to have better composite properties. The characteristics of the composites prepared are as detailed in Fig. 2, which also shows the optical and schematic diagram of the cross section of the different composites prepared. A and B in Fig. 2, denote the area of composite where, A is on either side of composite surface consisting mainly resin rich portion, whereas B is the central section having both fibres and resin.

\subsection{Wear tests}

Wear tests were carried out on a reciprocating sliding test rig, model TE 67/R, supplied by Plint and Partners (currently known as Phenoix Tribology Ltd. (UK)), having facilities to do the tribological experiments in different configurations such as, pin on plate/disc or ball on plate/disc, in controlled environments. By employing a special accessory, the tests can be conducted in lubricated conditions. In the present study the tests were conducted with a steel ball (AISI 52100) on composite plate samples. The experimental sequences can be explained by the three stages as illustrated below.

Initial experiments were conducted, in stage 1 , on biaxial nonwoven (BANW) reinforced vinyl-ester composite samples, to understand and optimise the tribological parameters for further tests. In this stage, the tests were conducted at various loads of $10,30,50,70,100$ and $150 \mathrm{~N}$, at constant stroke length $(6 \mathrm{~mm})$ and frequency $(1 \mathrm{~Hz})$, for two sliding distances: 21.6 and $43.2 \mathrm{~m}$.

In stage 2, tribological studies were conducted at a constant load of $100 \mathrm{~N}$ for the sliding distances of 2.7, 5.4, 10.8, 21.6, 43.2 and $64.8 \mathrm{~m}$ (corresponding to $7.5,15,30,60,120$ and $180 \mathrm{~min}$ ). The stroke length was fixed at $6 \mathrm{~mm}$ and the frequency at $1 \mathrm{~Hz}$. The tests were conducted on vinyl ester composite having different reinforcements (i.e., biaxial (BAWK), biaxial non-woven (BANW), triaxial (TAWK) and quadraxial (QAWK) oriented warp knit) to investigate which preform provides the good performance.

Further, in stage 3, the tests were conducted with quadraxial preform (QAWK) as a fixed reinforcement with different resins i.e., vinyl-ester (VE), epoxy (FR) and polyester (PE), at a load of $100 \mathrm{~N}$ and sliding distance of $64.8 \mathrm{~m}$. The stroke length and frequency were the same as in stage 2 . Two different tri-

\begin{tabular}{|c|c|c|c|c|}
\hline $\begin{array}{l}\text { Composites } \\
\text { (Glass DOS Preform/Resin) }\end{array}$ & $\begin{array}{l}\text { Laminae } \\
\text { Thickness, mm } \\
\text { (cv\% }<5 \text { ) }\end{array}$ & $\begin{array}{l}\text { Fibre volume } \\
\text { Fraction } \\
(\text { cv\% <6) }\end{array}$ & $\mathrm{A}, \mathrm{mm}$ & $\mathrm{B}, \mathrm{mm}$ \\
\hline Biaxial/NE & 0.94 & 0.40 & 0.02 & 0.90 \\
\hline Biaxial non-woven/NE & 0.96 & 0.37 & 0.02 & 0.92 \\
\hline Triaxial/VE & 0.95 & 0.31 & 0.09 & 0.86 \\
\hline Quadraxial/VE & 1.10 & 0.33 & 0.04 & 1.02 \\
\hline Quadraxial/Epoxy & 1.04 & 0.34 & 0.03 & 0.98 \\
\hline Quadraxial/Polyester & 1.67 & 0.20 & 0.22 & 1.23 \\
\hline
\end{tabular}

Fig. 2. Composite cross-section (optical and schematic diagram) and specification. 
bological service conditions were selected, i.e., unlubricated or dry and lubricated or aqueous (in presence of distilled water). Repeatability of the tests were analysed and error was found to be between $5-7 \%$ for the various tests.

Surface characterisations have been done with optical and scanning electron microscopy (SEM). The wear volume was estimated by measuring the dimensions of the wear track. The track is assumed to have perfect geometry as it was created by the perfect steel ball. To avoid error in wear profile measurements, the wear track was divided into three segments, and mathematical equations are employed to calculate the individual wear volume based on the test wear ball geometry. The total wear volume is calculated by the summations of each segment.

\section{Results and discussion}

The result of the stage 1 (Fig. 3), were used to select optimum tribological parameters, i.e., load and sliding distance. It depicts the variation of wear volume of biaxial non-woven (BANW) reinforced vinyl-ester composite tested under various loads: 10 , $30,50,100$ and $150 \mathrm{~N}$ for two sliding distances, 21.6 and $43.2 \mathrm{~m}$. Hence, the medium load of $100 \mathrm{~N}$ was selected for the further tribological tests in the next two stages.

\subsection{SEM examination of worn surfaces}

Fig. 4(a-h) show the SEM images of the worn surfaces for the composite specimens at selected conditions (load of $100 \mathrm{~N}$ ) in order to understand the mechanisms involved in the wear process. A full wear scar with a well-defined boundary, formed on the surface of BANW reinforced composite after the sliding distance of $64.8 \mathrm{~m}$, is shown in Fig. 4(a). The SEM image also shows the presence of voids on the surface (outside the wear scar), which is a drawback of composites prepared by hand-lay-up technique. To understand more clearly the worn surface morphology, the magnified images of the middle and left end of the same worn track are shown in Fig. 4(b) and (c). It is interesting observe the presence of exposed layers of fibres (Fig. 4(b)) and bundles of fibre (Fig. 4(c)). A highly deformed worn surface on the BAWK composite is shown in Fig. 4(d). Interestingly, a sim-

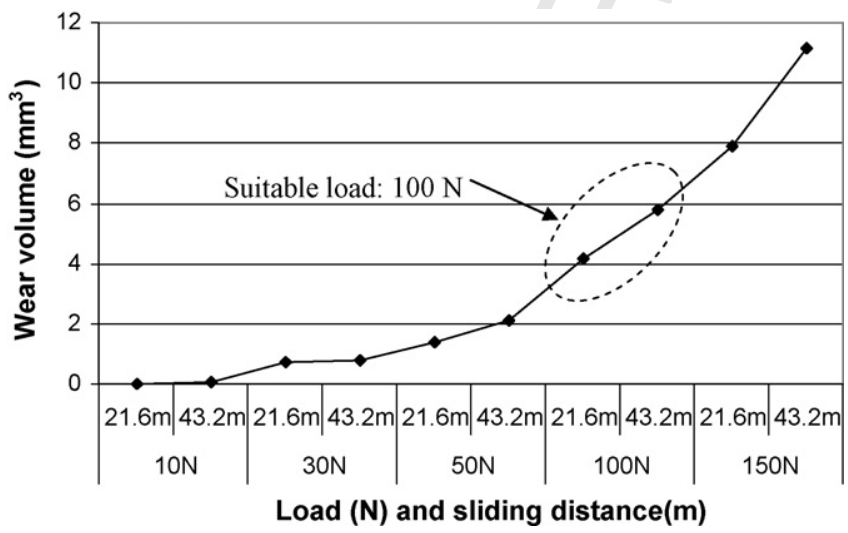

Fig. 3. Variation of wear volume as a function of normal load (10, 30, 50, 100, $150 \mathrm{~N})$ and sliding distances of $(21.6,43.2 \mathrm{~m})$ for vinyl ester composites with BANW preform. ilar image of the worn surface of TAWK composite (Fig. 4(e)) does not show much exposure of the fibres. Another remarkable feature of the worn surface on QAWK composite is shown in Fig. 4(f), where the internal cavity is formed because of the separation of the layers and removal of matrix resin. Fig. 4(g) and $(\mathrm{h})$ show the images of the worn surfaces on the epoxy resin QAWK reinforced composites with dry and wet test conditions respectively. The layer of resin retain on the worn surface is very clear from the Fig. 4(g). In wet condition, Fig. 4(h) shows slightly polished surfaces regions and layers of fibre without much distinction compared to the dry condition. From the SEM images, the presence of particular zones A, B, C, D and E are very clear, which are explained in Section 3.4.

\subsection{Variation of wear volume and evolution of friction coefficient for reinforced composites with different fibre preforms}

The results from wear tests with composite samples having different preforms, i.e., BANW, BAWK, TAWK, and QAWK, during the stage 2, are shown in Fig. 5(a). It is clear that there is an initial increase in the wear volume for all the composites. Further there is a gradual increase in the wear volume with sliding distance for all the preforms except for BANW composite, which shows a sudden increase in wear volume beyond $20 \mathrm{~m}$ sliding distance.

The low wear resistance of the BANW reinforced composite could be due to the presence of non-woven layer in the fabric structure consisting of small length of fibres in random directions. This non-woven layer in the composite would wear-out rapidly as the fibres are loosely held in the preform. In addition, the easily removed fibrous particles could increase the wear by acting as abrasive particles. It is evident from Fig. 5(a) that the BAWK reinforced vinyl ester composite is showing very low wear volume compared to the other three composites. It could be because of the higher fibre volume fraction of the composite along-with better interface properties of the composite due to lower linear density of the glass yarn in the preform. It could be noticed that fibre volume fraction has a significant effect on the wear resistance of these warp knit preformed composites. It is evident from wear volume (Fig. 5(a)) and composite specification (Fig. 2) that the composite having higher volume fraction (BAWK) is the one with best wear performance. Isotropic properties of the glass fibre used for the preform might have neutralised to some extent the influence of fibre orientation on tribological properties.

Fig. 5(b) shows the evolution of friction coefficient values during the sliding process. It is very clear that it has a sudden increment period for short sliding distance, reaching to an almost stabilised value. Also, it is interesting to note that the composite with BANW shows high friction values (around 0.80) compared with the other three composites, which have almost steady-state value (around 0.60). The fibrous particles in the BANW composite could be the reason for the higher friction coefficient values. The slight fluctuation in the friction coefficient is possible due to the periodic ploughing and rolling action of the wear particles formed during the sliding process [15]. 
(a)

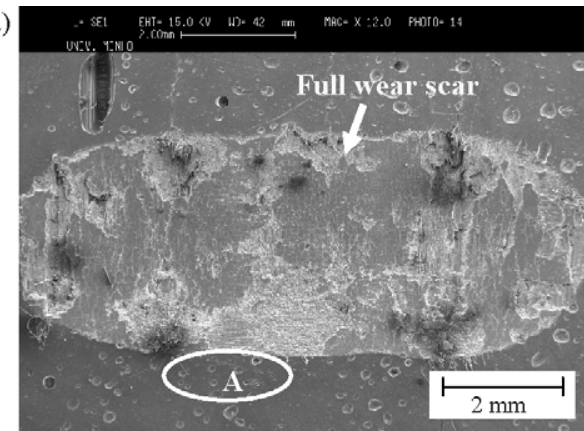

(c)

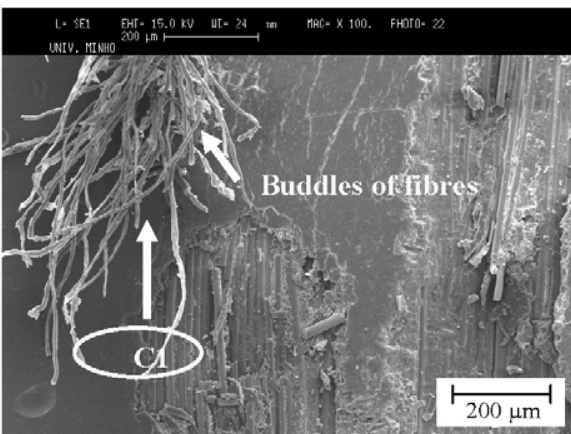

(e)

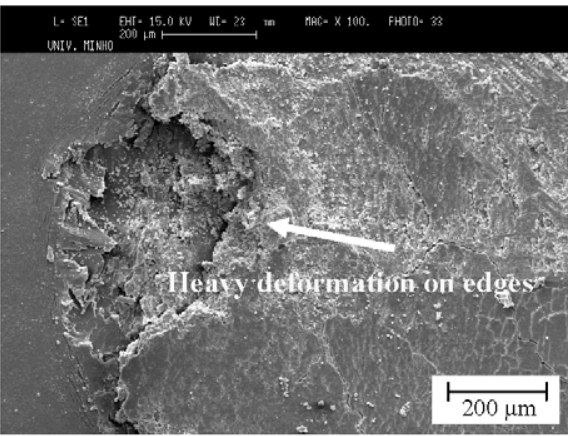

(g)

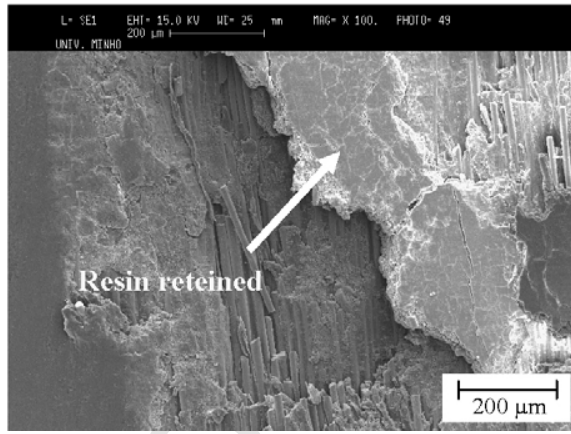

(b)
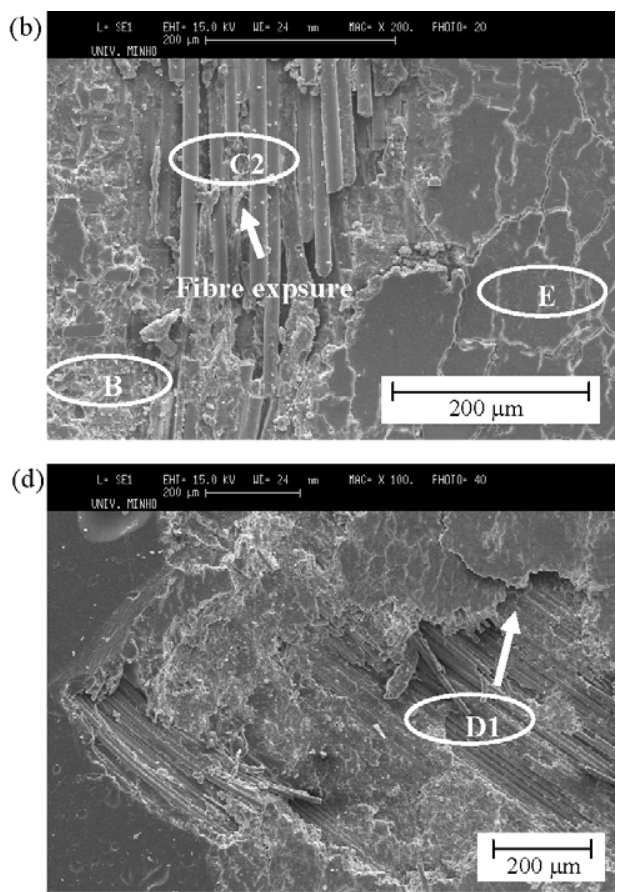

(f)
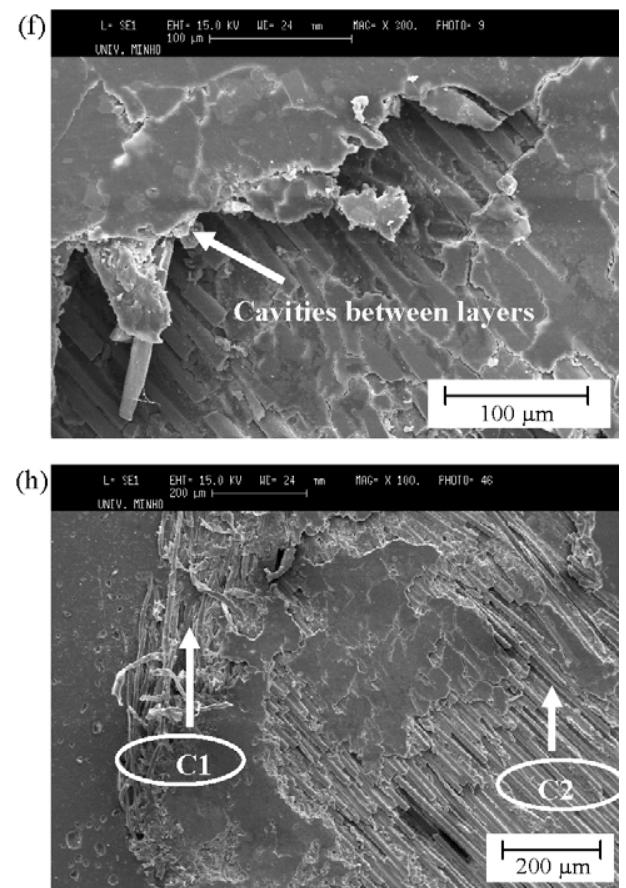

Fig. 4. SEM images of the worn surfaces after $64.8 \mathrm{~m}$ sliding distance. (a) BANW, vinyl ester, complete wear scar, dry. (b) BANW, vinyl ester, middle, dry. (c) BANW, vinyl ester, left, dry. (d) BAWK, vinyl ester, left, dry. (e) TAWK, vinyl ester, left, dry. (f) QAWK, vinyl ester, left, dry. (g) QAWK, Epoxy, dry. (h) QAWK, Epoxy, lubricated.

dry and lubricated sliding at $100 \mathrm{~N}$ load. It is clear that polyester is the less wear resistant composite in both dry and wet conditions. An intermediate wear resistance is shown by vinyl ester composite and the best performance is observed for epoxy resin composite. The results also show that there is a minor reduction in wear volume in lubricating sliding conditions for all the composites. This behaviour is mainly ascribed by the lubricating and cooling effect of water at the contact zone. However, the above effects are not very

Please cite this article in press as: M.T. Mathew et al., Tribological properties of the directionally oriented warp knit GFRP composites, Wear (2007), doi:10.1016/j.wear.2006.12.001 

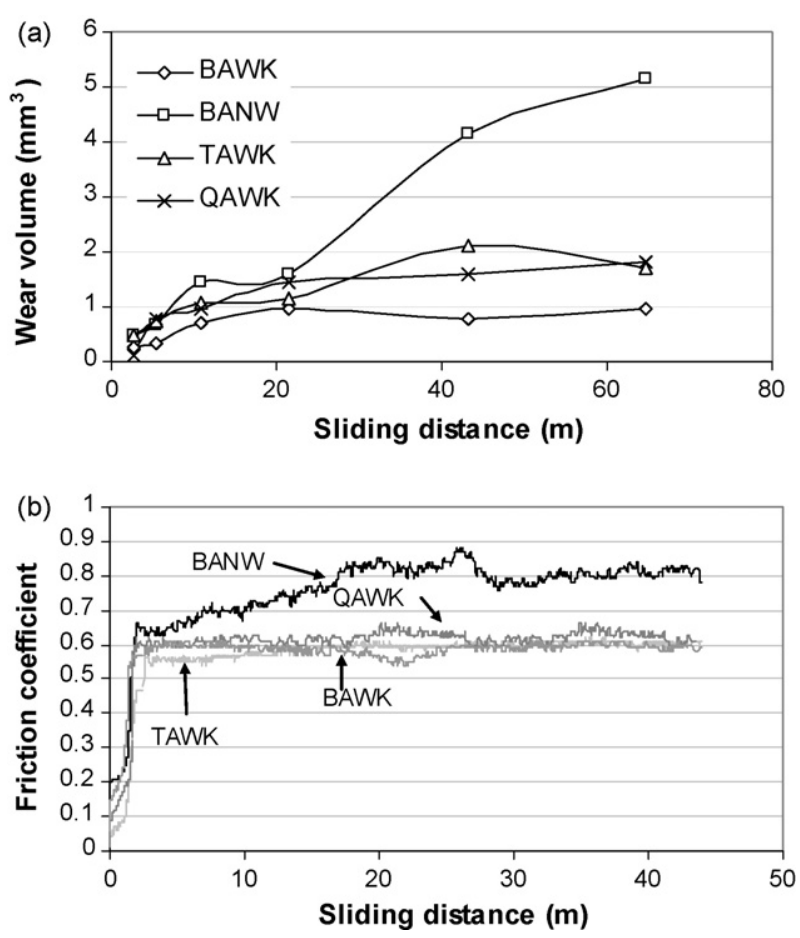

Fig. 5. Tribological performance of vinyl ester composites with various preforms (BANW, BAWK, TAWK, QAWK) in dry conditions at $100 \mathrm{~N}$ normal load. (a) Variation of the wear volume as a function of sliding distance. (b) Evolution of the friction coefficient values for a sliding distance of $43.2 \mathrm{~m}$.

predominantly affecting the wear behaviour of the composites due to the unique behaviour of polymers in the presence of water. It includes water absorption and the formation of a transfer film on the counterface (steel ball), which was observed immediately after each test.

In the current study, the load was kept constant; however, the effect of surface or rather contact temperature could not be neglected [16]. Moreover, the worn particles that are trapped in the contact zone will have an effect on the wear process. It is well established that the wear volume may be significantly affected by worn particles, depending on their properties, such as size, geometry, hardness etc. In the present study, two types of worn particles may be generated, namely, from resin and fibre. The presence of the worn particles may even change the wear mechanisms from two-body to a three-body process [17-20].

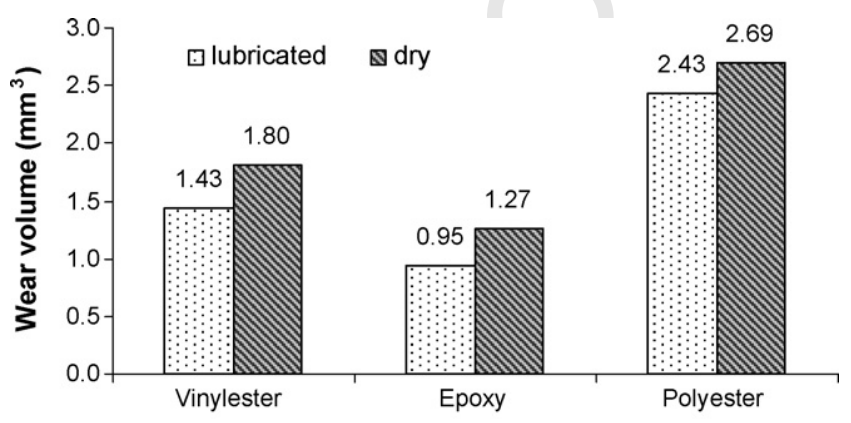

QAWK reinforced composite with different resins

Fig. 6. Wear volume for different resins reinforced with QAWK preform in dry and lubricated conditions for a sliding distance of $64.8 \mathrm{~m}$ at $100 \mathrm{~N}$ normal load.
As mentioned earlier, the epoxy resins are more adhesive and protective and also having better mechanical properties, chemical resistance and electrical characteristic compared to the other resins [21]. Further, epoxy resins have low friction coefficient, which was very clear from the current study, and low thermal expansion, which provided them with higher load bearing capability [22]. Hence, it is not very surprising the better tribological performance of composites with epoxy resins in the obtained results.

In reciprocating sliding conditions, the sliding speed attains a maximum value at the middle and reduces to zero at the two ends of the stroke. So, there is a possibility of more severe wear at the two ends than in the middle, which is very clear in the SEM images (Fig. 4(c) and (h)). Further, the reduction in sliding speed increases the force distribution per unit area at the contact interface, which contributes to the severe wear at the two ends of the stroke.

(b) Evolution of friction coefficient

The evolution of friction coefficient at $100 \mathrm{~N}$ of normal load for different resins reinforced with QAWK preform for dry and lubricated conditions is shown in Fig. 7(a) and (b), respectively. As expected, higher friction values are observed for dry condition $(0.50-0.70)$ than for lubricated condition $(0.30-0.40)$. It is clear that the polyester is exhibiting the higher friction coefficient values. In lubricated condition (Fig. 7(b)) the increment of the friction coefficient values are also observed for epoxy and vinyl ester, but for longer sliding distances, which is attributed

256 257 258 259 260 261 262 263 264 265 266 267 268 269 270 271 272 273 274 275 276 277 278 279 280 281 282 283
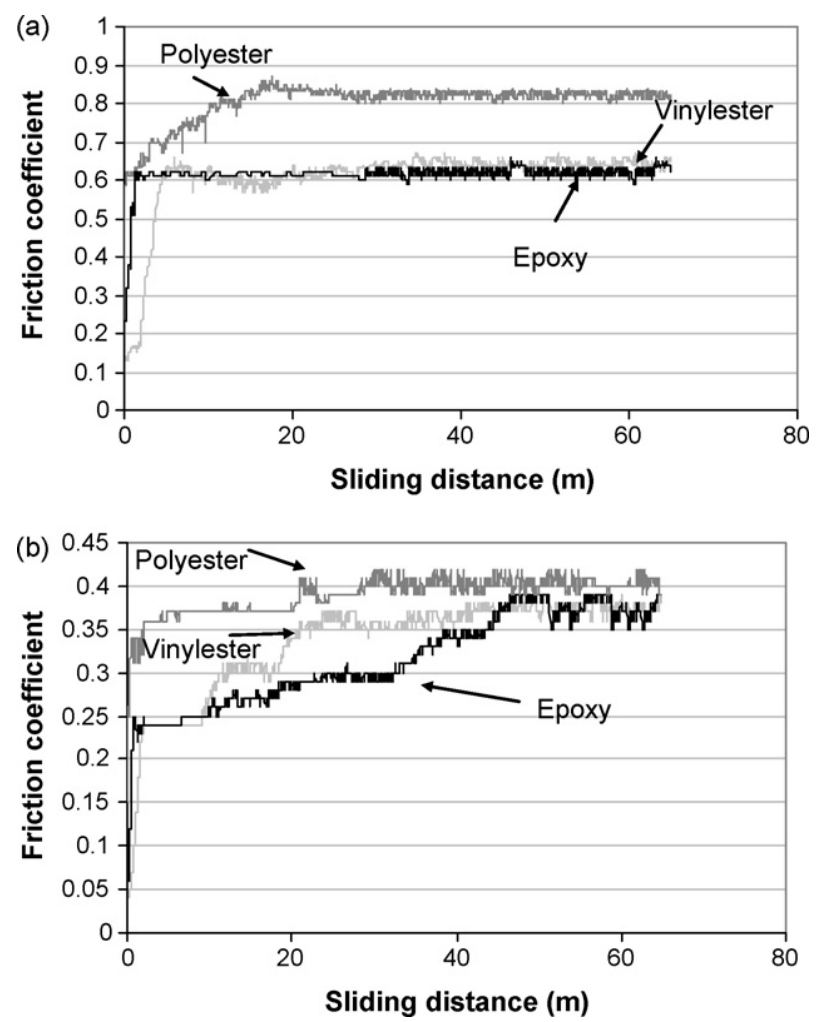

Fig. 7. Evolution of friction coefficient for different resins reinforced with QAWK preform for a sliding distance of $64.8 \mathrm{~m}$. (a) Dry conditions. (b) Lubricated conditions. 
to the interaction with fibre and matrix layers. Earlier studies on the effect of fibre reinforcement on the friction and wear of polyamide 66 under dry rolling and sliding contact, mentioned that wear rates and friction coefficient values are determined by the nature and behaviour of the different layers and by the strength of its bond with the underlying material $[15,16]$.

\subsection{Schematic diagram of the contact zone and mechanisms involved in the sliding process}

In order to understand the mechanisms in the tribological process of the composites, a schematic diagram of the wear scar (contact zone) is presented in the Fig. 8. The structural properties of these composites are very complex, as observed from the schematic diagram and layer properties, illustrated in Figs. 1 and 2. For the purpose of explaining the wear mechanisms, a simple structured composite having four layers (Fig. 8) was considered. In this structure, the top and bottom layers are made of pure resin; layer 2 is having the fibres that are oriented parallel to the sliding direction and layer 3 is having fibres perpendicular to the fibre direction of layer 2 . However, it should be noted that in the real situation, there is presence of resin within the fibres in layers 2 and 3 and the interface layer will also be formed between each layer. Moreover, the directions of the fibres may be other than $90^{\circ}$ - for example 0 or $45^{\circ}$, as shown in Fig. 1 .
Further, there are also knitting fibres interlocking these layers in the $\mathrm{z}$ direction.

The schematic top view of the wear path after the sliding process (Fig. 8) can be divided into various zones. The outermost region, zone A, around the wear path, is where the worn particles are spread. Inside that is the zone B, in which is the worn inclined surface of the pure resin of layer 1 of the composite. Further, zone $\mathrm{C}$, shows the worn surface of layer 2 that consists of two sub-zones, $\mathrm{C} 1$ and $\mathrm{C} 2$. The sub-zone $\mathrm{C} 1$ is located at the top and bottom short edges of the wear path, which is characterised by the presence of bundles of broken fibres. Sub-zone $\mathrm{C} 2$ represents the left and right long edges of the wear path. This zone is characterised by the unbroken long fibres as the part of composites. Further region D, a worn surface of layer 3 , also has two distinguished sub-zones D1 and D2, which are similar to $\mathrm{C} 2$ and $\mathrm{C} 1$ respectively (explained in Fig. 8). Finally, there is a region $\mathrm{E}$, which is the bottom part of the layer made of pure resin. The possible locations of such zones on the worn surfaces are identified in the SEM images, (see the marked zones in Fig. 4(a-h)).

During the sliding process, after the penetration of top layer of resin, layer 1, the ball will contact layer 2, where it is interacting with fibres parallel to the sliding direction. Here, the frictional properties of the fibre will definitely affect the ball movement. During sliding interactions, the fibres will be broken down and gathered together at the two ends, which was very clear in the

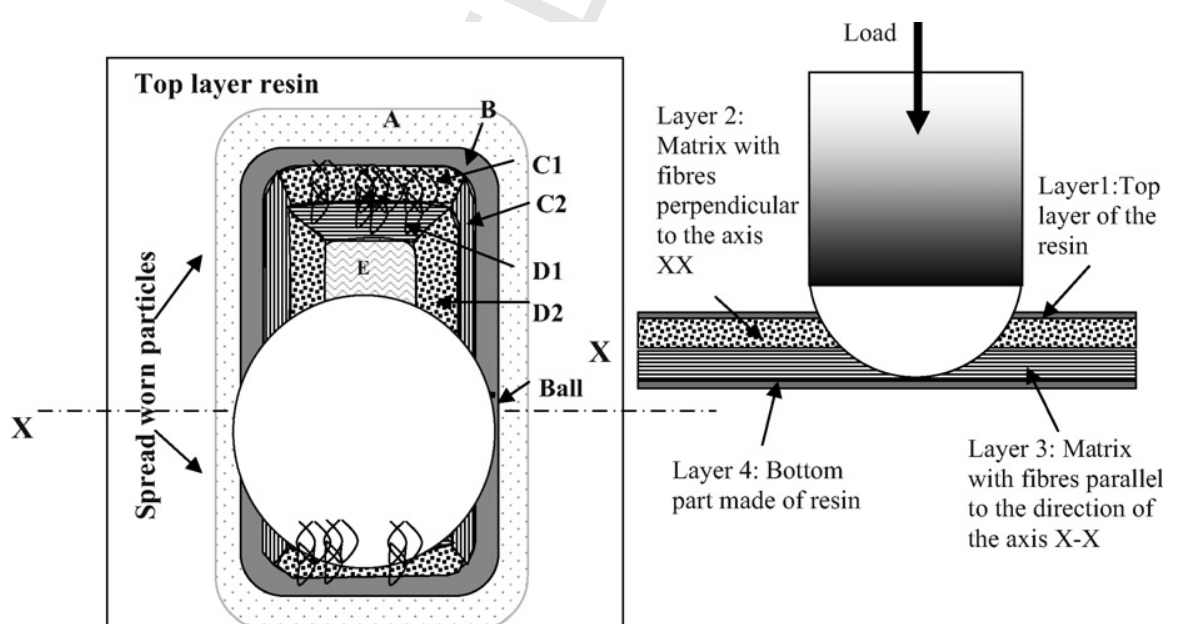

Top view

Cross sectional view at $\mathrm{X}-\mathrm{X}$

Zone A: Outside the worn surface where the particles are spread

Zone B: Worn surface on resin

Zone $\mathrm{C} 1$ : Worn surface at the top and bottom edge of layer 2 with fibre perpendicular to the axis $\mathrm{X}-\mathrm{X}$ and left and right sides of the layer 3 with fibre parallel to axis $\mathrm{X}-\mathrm{X}$
Zone C2 \& D1: Worn surface at the left and right edges of the wear path on layer with fibre directed perpendicular to the axis X-X (layer 2) and parallel (layer 3)

Zone D2: Worn surface of the wear path at the top and bottom part with fibre parallel to the axis $\mathrm{XX}$

Zone E: Worn surface at the bottom part of the wear scar, part of layer 4 .

Fig. 8. Schematic diagram of the wear scar (contact zone) of the contact plate. 
SEM images, (Fig. 4(c)). Moreover, depending on the nature of the interface between matrix and fibre and the force distribution during the sliding process, debonding of fibre from the matrix will occur, which may further lead to the formation cracks in each layer. Particularly in the case of polymers, adhesion forces between the matrix, fibre and counterface (steel ball) must also to be considered as influencing parameters on the material removal.

In layer 3, the ball will contact fibres oriented perpendicular to the sliding direction, where it is expected to have more resistance to sliding, compared to that in layer 2 . The worn surface generated on the layer 4, resin, is shown in region E. Hence the dimensions of the layers made of resin and fibres, properties and directions of fibres and interfacing layers will strongly influence the sliding process and the material loss. As mentioned before, the wear debris formed during the process is also a strong influencing factor. Depending on the nature and geometry of the wear debris, the abrasion process can be accelerated by their cutting and grooving effects. It is also clear that the presence of voids and porous structure also play a role in the mechanisms involved during the sliding process. Hence, the major mechanisms involved in the sliding process are adhesion wear (ball, fibre and matrix), abrasive wear (twobody and three-body) and fibre fracture and fragmentations $[6,7,23-25]$.

The structure made of fibre and resin (for example layers 2 and 3 in the schematic diagram of Fig. 8) in reinforced composites acts as a means to transfer load and stress distribution between the fibres, providing a barrier against adverse conditions, and increasing the wear resistance [25-28]. Hence the stabilised/constant values of the wear volume at longer sliding distances (Fig. 4(a)), can be justified.

\subsection{Wastage maps as a function of selected variables}

Wastage maps are useful to obtain a clear picture of the tribological process. They are basically schematic diagrams showing the process as a function of selected parameters [29,30]. In this study, such a map is developed as a function of sliding distance and composite preform. The following notations were used:

Low : $v<1$

Medium : $\quad 1<v<2$

High : $\quad v>2$

where ' $v$ ' is wear volume expressed in $\mathrm{mm}^{3}$.

Fig. 9 shows the wastage map as a function of different preforms and sliding distances. The low region is located for all the preforms at short sliding distances. As discussed earlier the composites with BANW reinforcement are showing poor performance, by the transition from low to medium and finally to high region. Next to this, TAWK and QAWK reinforced composites show low region and medium region. Finally the BAWK composites demonstrate the best performance by the presence of a predominant low wastage zone. This could be explained by the fibres of the biaxial warp knit preform characteristics, having

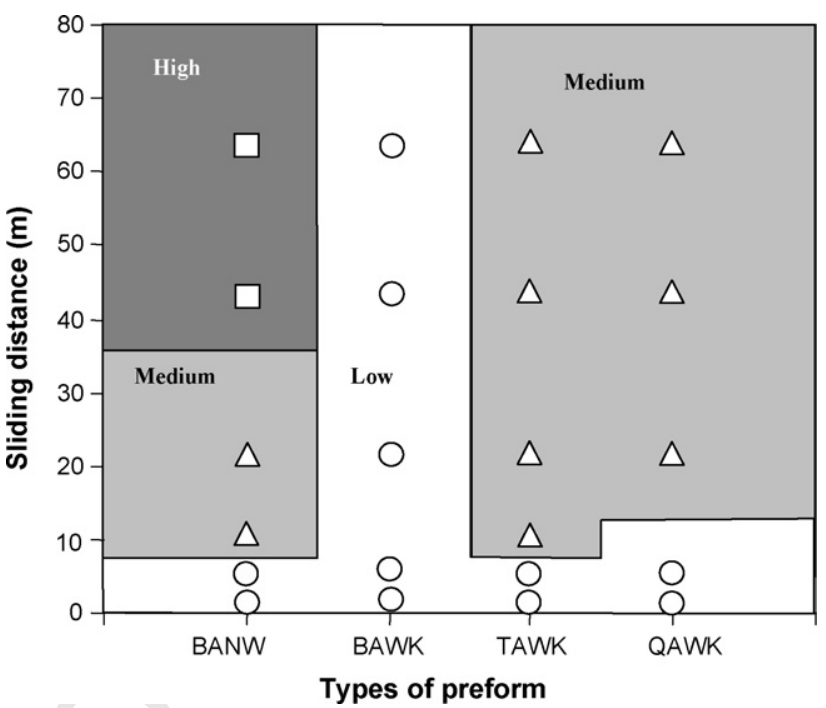

Fig. 9. Wastage map for vinyl ester composites as function of a sliding distance and type of preforms.

least yarn count in its fabric construction which could provide better interface between the fibre-resin region due to higher surface area of the fibres. As it was mentioned in previous section and Fig. 8, the changes in the wear mechanisms acting in each layer during sliding process also have a significant role in the distribution of different regions in the map.

The tribological properties of such textile composites are very complex and influenced directly and indirectly by several parameters. Therefore, more investigations are required based on the specific applications of these materials. Further, to overcome the inherent void and porous structure of the composites resulted from hand lay-up technique other methods of preparation can be adopted.

\section{Conclusions}

The tribological performance of the GFRP composites with different directionally oriented warp knit structures and resins were analysed. The following conclusions can be derived from the study:

- The influence of fibre orientation in the preform was insignificant but the fibre volume fraction has a strong effect on the tribological performance of these composite laminates.

- Biaxial warp knit (BAWK) preformed composites and composites with epoxy resin are showing the best tribological properties.

- Different wear mechanisms, (adhesion, abrasion and fibre fracture and fragmentation) acting at the contact zone were identified and it is observed that the properties of each layer, made of resins and fibres, have strong influence on the obtained wear values.

- A wastage map for the composites was developed as a function of sliding distance and type of preform. Such map is a very useful tool to understand the performance of such composites, in different conditions. 


\section{Acknowledgement}

This work is being conducted within the Asia-Link Programme, the authors wish to thank the European Commission for awarding research programme under the EU Asia-link project to the Indian Institute of Technology—Delhi (New Delhi, India) and University of Minho (Portugal). Authors are also thankful Changzhou Hongfa Composites Engineering Company Limited, China for providing the samples for the present study.

\section{References}

[1] D. Hull, An Introduction to Composite Materials, Cambridge university press, Cambridge, UK, 1982.

[2] J.W.S. Hearle, Textiles for composites a business opportunity for the $21 \mathrm{st}$ century, Part I, Textile Horizons 14 (6) (1994) 12-15.

[3] V. Ogale, R. Alagirusamy, Textile preforms for advanced composites, Indian J. Fibre Textile Res. 29 (9) (2004) 366-375.

[4] J.K. Lancaster, The effect of carbon fibre reinforcement on the friction and wear of polymers, Br. J. Appl. Phys. (J. Phys. D.) Ser. 21 (1968) 549-559.

[5] V.K. Srivastava, J.P. Pathak, K. Tahzibi, Wear and friction characteristics of mica-filled fibre-reinforced epoxy resin composites, Wear 152 (1992) 343-350.

[6] B.S. Tripathy, M.J. Furey, Tribological behaviour of unidirectional graphite-epoxy and carbon-PEEK composites, Wear 162-164 (1993) 385-396.

[7] N. Sung, N.P. Suh, Effect of fibre orientation on friction and wear of fibre reinforced polymeric composites, Wear 53 (1979) 129-141.

[8] H.W. Chang, Wear characteristics of composites: effect of fibre orientation, Wear 85 (1983) 81-91.

[9] N. Wada, Y. Uchiyama, Friction and wear of short-fibre-reinforced rubber composites under various sliding speeds and loads, Wear 162-164 (1993) 930-938.

[10] P. Samyn, J. Quintelier, W. Ost, P.D. Baets, G. Schoukens, Sliding behaviour of pure polyester and polyester-PTfe filled bulk composites in over load conditions, Polym. Test. 24 (2005) 588-603.

[11] X. Yang, W. Wu, O. Jacobs, B. Schadel, Tribology behaviour of UHMWPE/HDPE blends reinforced with multi-wall carbon nanotubes, Polym. Test. 25 (2006) 221-229.

[12] N.K. Myshkin, M.I. Petrokovets, A.V. Kovalev, Tribology of polymers: adhesion, friction, wear and mass-transfer, Tribol. Int.1 38 (2005) 910-921.

[13] S.C. Anand, Warp knitted structures in composites, in: Proceedings of the Seventh European Conference on Composite Materials, vol. 2, London UK, 1996, pp. 407-413.
[14] T.W. Chou, F.K. Ko, Textile Structural Composites, Elsevier science, Amsterdam, 1989.

[15] S. Bahadur, V.K. Polineni, Tribological studies of glass fabric-reinforced polyamide composites filled with $\mathrm{CuO}$ and PTFE, Wear 200 (1996) 95104.

[16] S.N. Kukereka, C.J. Hooke, M. Rao, P. Liao, Y.K. Chen, The effect of fibre reinforcement on the friction and wear polyamide 66 under dry rolling-sliding contacts, Tribol. Int. 32 (1999) 107-116.

[17] A. Zhifei, C. Yanhua, Z. Limin, Micromechanical damage modelling of fibre/matrix interface under cyclic loading, Compos. Sci. Technol. 65 (2005) 1203-1210.

[18] A.P. Harsh, U.S. Tewari, Two-body and three-body abrasive wear behaviour of polyaryletherketone composite, Polym. Test. 22 (2003) 403-418.

[19] J.B. Donnet, Nano and micrcomposites of polymers elastomers and their reinforcements, Compos. Sci. Technol. 63 (2003) 1085-1088.

[20] X.F. Yao, M.H. Kolstein, F.S.K. Bijlaard, W. Xu, M. Xu, Tensile strength and fracture of glass fibre-reinforced plastic (GFRP) plate with an eccentrically located circular hole, Polym. Test. 22 (2003) 955-963.

[21] P.V. Vasconcelos, F.J. Lino, A.M. Baptista, R.J.L. Neto, Tribological behaviour of epoxy based composites for rapid tooling, Wear 260 (2006) 30-39.

[22] Kishore, P. Sampathkumaran, S. Seetharamu, S. Vynatheya, A. Murali, R.K. Kumar, SEM observations of the effects of velocity and lad on the lasing wear characteristics of glass fabric-epoxy composites with different fillers, Wear 237 (2000) 20-27.

[23] K. Friedrich, R. Reinicke, Zhang, Wear of polymer composites, J. Eng. Tribol. Part J 216 (2002) 415-426.

[24] J. Cayer-Barrioz, D. Mazuyer, Ph. Kapsa, A. Chateauminois, G. Robert, Abrasive wear micro mechanisms of oriented polymers, Polymer 45 (2004) 2729-2736.

[25] H. Pihtili, N. Tosun, Investigation of the wear behaviour of a glass-fibrereinforced composite and plain polyester resin, Compos. Sci. Technol. 62 (2002) 367-370

[26] H. Pihtili, N. Tosun, Effect of load and speed on the wear behaviour of woven glass fabrics and aramid fibre-reinforced composites, Wear 252 (2002) 979-984

[27] El-Tayeb, I.M. Mostafa, The effect of laminate orientations on friction and wear mechanisms of glass reinforced polyester composite, Wear 195 (1996) 186-191.

[28] P.K. Mallick, Fibre-reinforced Composites: Materials, Manufacturing and Design, Marcel Dekker, New York, 1988

[29] M.M. Stack, Mapping tribo-corrosion process in dry and in aqueous conditions: some new directions for millennium, Tribol. Int. 35 (2002) 681689.

[30] M.M. Stack, M.T. Mathew, Micro-abrasion transitions of metallic materials, Wear 255 (2003) 14-22. 